\title{
Employer engagement within 14-19 Diploma development
}

Andrea Laczik and Caroline White

Centre for Education and Industry, University of Warwick, Coventry, UK

Laczik, A. \& White, C. (2009) Employer engagement within 14-19 diploma development, Research in Post-Compulsory Education, 14:4 400413

\section{Abstract}

Formatted: Font: (Default) Times New Roman, 12 pt, Bold

In 2005, the UK government announced the development of a suite of employer designed Diplomas for 14-19 year olds linked to different industrial and commercial sectors. This article will reflect on some of the achievements and challenges of this major employer engagement initiative by drawing on three pieces of research: a review of Diploma development and two employer consultation studies belonging to the latest phase of Diploma development - the Diplomas in Humanities and Social Sciences and Languages and International Communications. The article suggests that meeting the needs of employers in qualification design is problematic as employers are a heterogeneous group bringing a range of different views, ideas and contributions to the process. Furthermore, the article points to a possible mismatch between policy makers' expectations from employers at macro level, and what in fact happens at local, micro level due to personal and economic circumstances, companies' demands and the economic climate.

Keywords: employer engagement, qualification development, Diplomas, 14-19 education, Diploma Development Partnerships. 


\section{Introduction}

In 2005, the UK Government announced the development of a new system of 14-19 education offering a range of curriculum choices tailored to the needs of individual young people (DfES, 2005). The new system aspired to raise participation rates in UK post-compulsory education from one of the lowest in the OECD countries to one of the highest and reduce disaffection within compulsory education (H.M.Treasury, 2004). An intrinsic part of the new system of 14-19 education would be a new suite of employer designed Diplomas for 14-19 year olds comprising 14 lines of learning linked to different industrial and commercial sectors (DfES, 2005). Subsequently another three lines were introduced in 2007. Sector Skills Councils (SSCs) had been established by Government in 2002 to articulate the 'voice' of employers (Lloyd, 2008). Accordingly the UK Government assigned responsibility for the design of the new Diplomas to the relevant SSCs in England (DfES, 2005). Consequently, SSCs convened Diploma Development Partnerships (DDPs) comprising employers, Higher Education (HE) providers, education professionals, and other key stakeholders to draw up the line of learning for each Diploma. This article will reflect on some of the achievements and challenges of this major employer engagement initiative.

There is a dearth of literature on employer engagement in qualification design outside of Government policy documents and guides. However, commentary surrounding the development of the new Diplomas (Keep, 2005; House of Commons Education and Skills Committee, 2007; Hodgson and Spours, 2007; Nuffield 14-19 Review, 2007) together with research into the role of the SSCs in employer engagement (Payne, 2008; Lloyd, 2008) raises concerns over the ability of SSCs to articulate employer needs. This article will draw on three research projects commissioned by the Qualifications and Curriculum Authority (QCA) to inform the Diploma development process (Ertl et al, 2009; Stanley, 2009; Muir, 2009a, b) as a lens through which achievements and issues surrounding employer engagement with qualification design can be explored. 


\section{Employer Engagement Past and Present}

Engaging employers in young people's education and training is not a new phenomenon. There have been a range of employer engagement initiatives since the 1973 Education (Work Experience) Act. Subsequent initiatives include, for example, the Technical and Vocational Education Initiative from 1983-1997, Industry Year in 1986 and its ensuing 'Industry days', and the establishment of the National Education Business Partnership Network in 1998.

What is new is the intensity and scale of employer engagement demanded by the UK New Labour Government. The National Council for Educational Excellence (NCEE) document 'Building Stronger Partnerships. Employers: How You Can Support Schools, Colleges, Children and Families' (DCSF, 2008a) is the latest pronouncement of a Government employer engagement policy which demands more and more from employers. The document (DCSF 2008a), describes itself as a guide on how employers can engage with education. However, its content is rhetorical rather than research based and echoes motifs found in previous documents of its kind (DfES 2003a; DfES, 2003b) extolling employer engagement as a magical cure for a host of educational issues. Its central message is that employers' contributions can be achieved in a 'simple, effective and rewarding way' and that partnerships between employers and education are 'a two-way street' (DCSF, 2008a: Foreword). The following points exemplify how Government would like employers to engage with education:

- Helping to develop and deliver the new Diplomas

- Supporting enterprise education in schools,

- Providing work experience for students,

- Providing professional development placements for school and college staff,

- Visiting schools to give talks, or help out in lesson time,

- Mentoring school and college leaders. 
Government publications and information sources assert that Diploma qualifications have been designed by employers (DCSF, 2008a; DCSF, 2008b; www.direct.gov.uk/Diploma, 2009). Additionally, the NCEE (DCSF, 2008a) states that the Diploma will deliver what employers and universities are looking for in new recruits and new students.

However, commentary surrounding the development of the new Diplomas and the role of the SSCs raises questions about the ability of SSCs to articulate employer needs, in particular the needs of Small and Medium Enterprises (SMEs) (Keep, 2005; House of Commons Education and Skills Committee, 2007; Nuffield 2007; Payne, 2008). Payne's study exploring SSC employer engagement strategies reports that larger firms were on the whole easier to engage at all levels and points to the ever-present danger of SSCs tapping into the view of a 'steadfast minority' (Payne, 2008: 109). Furthermore, a systematic review (Scesa and Williams, 2008) examining employer engagement in HE course development reports that large organisations are traditionally more likely to engage in course development than smaller ones due to larger resources and capacity. However, the review's findings also suggest that engaging employers through employer networks is beneficial due to the time-consuming nature of maintaining effective communication with a large number of SME employers. In this light, SSC use of employer networks and larger employers might arguably be the most efficient approach to employer engagement within SSC resources, if not the most ideal.

Additionally, Lloyd's study (2008) of skills needs in the fitness industry questions the ability of SSCs to represent the heterogeneity of their sector. Lloyd (Lloyd 2008) reports that a complex picture exists across the fitness industry over desired levels of qualifications or social skills and attributes, depending on an organisation's broader business strategy and the local labour market. Lloyd (2008) argues that the ability of SSCs to identify a coherent 'demand' from employers is clearly difficult even for what is a fairly narrowly defined occupational group. 
This article will draw on three Diploma development research projects (with which the authors have been involved) as examples of employer engagement: a review of Diploma development (Ertl et al, 2009) and two employer consultation studies for the latest phase of Diploma development (Stanley, 2009; Muir, 2009a, b). The next section will briefly outline the 14-19 Diplomas before proceeding to consider these research projects.

\section{4-19 Diplomas}

The Diploma is arguably the most sophisticated manifestation of employer engagement to date.

Employers are involved through DDPs, Diploma development consultations and Diploma delivery consortia. Furthermore, through the NCEE guide (DCSF 2008a) Government is suggesting an even deeper involvement from employers by providing support for the whole delivery of Diplomas. For example, through 10-day quality work experience placements, shorter work based visits for small groups of learners, supporting the Project qualification within the Diploma, professional development placements for teachers, and production of materials for teachers and college lecturers (DCSF 2008a).

The key concept of the Diplomas is the acquisition of knowledge and skills through applied learning. Initially, the Diploma concept included 14 lines of learning linked to employment sectors to be implemented in three phases from 2008. However, in 2008 three more lines of learning were announced: Humanities and Social Sciences, Languages and International Communication, and Sciences, for first teaching in 2011. Although these three lines of learning are not linked to any specific employment sector their development is being managed by Sector Skills Councils: namely Humanities by 'Creative and Cultural Skills', Languages by 'GoSkills' (the SSC for passenger transport) in partnership with the National Centre for Languages, and Science by the 'Science, Engineering and Manufacturing Technologies association' (SEMTA).

The first phase of Diplomas, which has been available since September 2008, includes IT, Society Health and Development, Construction and the Built Environment, Engineering, and Creative and Media. The 
second phase of Diplomas comprises Environmental and Land-based, Manufacturing and Product Design, Hair and Beauty Studies, and Business, Administration and Finance, and will be available from September 2009. The third phase - Public Services, Sport and Active Leisure, Retail Business and Travel and Tourism - will be offered from September 2010, and the fourth and final phase - Humanities and Social Sciences, Languages and International Communications, and Sciences - will be introduced from September 2011(the Level 3 Science Diploma will be launched in 2012).

This article will turn to an evaluation of the first three phases of Diploma development (Ertl et al., 2009). The evaluation offers an overview of employer engagement during the pre-delivery phase of the Diploma, and investigates its function as part of the preliminary research and consultation within each line of learning. The section on two of the Phase 4 Diplomas concentrates on specific examples from the overall consultation process with employers.

\section{Reviewing Diploma Development}

The project, Reviewing Diploma Development (Ertl et al., 2009) was conducted over a period of 12 months during 2007-08, and concentrated on the first 14 Lines of Learning as case studies. Data were generated by interviewing Diploma Development Partnerships' representatives, many of whom were not employers but at least had knowledge about the consultation processes with employers. A semi-structured interview schedule was developed and used with every interviewee. A section of the interview schedule concentrated on strategies DDPs used to identify skills' gaps, current and emerging employment needs, and on processes DDPs used for consulting key stakeholders, such as employers. All information generated through consultation and research was debated and fed into the specific qualification development.

Employers were drawn into the Diploma development process from the very beginning of the work on the new qualification. For each Diploma phase official guidance documents (QCA et al., 2005, 2006, 2007) outlined the set-up of the DDPs, the representation of the key stakeholders, and the roles and 
responsibilities of the DDPs and their working groups. Employers were expected to get involved at the initial stages of the Diploma development and have an input into the vision for Diplomas, they were to offer their knowledge on skills demand in the labour market, their views on skills, knowledge and competences demanded at company level, they were to generate input into the Diploma content, and feedback on materials produced by the DDPs as the qualification developed.

According to the QCA guidance documents, each DDP was to set up an employer-led Steering Group. The appointment of the Chair of the Steering Group happened in a variety of ways; through invitation, volunteering and/or recommendations. Similarly their engagement, in terms of time and commitment show differences. Some Chairs were in full-time employment and they had to be more careful about the extent to which they got engaged with the detailed development process of the qualification. Nevertheless, their contribution should not be underestimated; they were often selected for their reputation, knowledge of the sector, more strategic thinking and effective chairing of sessions. Other DDPs attracted Chairs who already had retired. These employers were equally well-respected in their sector, but additionally they also had the time to engage in the more detailed work of the particular Diploma line. This clearly was a further benefit to the DDP. All Chairs worked as volunteers, without receiving any immediate return to them or to their company.

Having been involved now for 15 months, what I can say is that nobody who was actually employed in a job, either self-employed running their own company, or working for another company in whatever capacity would be able to spend the time that I've spent on this Diploma. It is very, very demanding as far as time is concerned. (Steering Group Chair)

Interview evidence shows that employers were also expected to contribute through other working groups that were set up independently by each DDP according to their needs. Examples of such other working groups are Quality Group, Employer Advisory Group, and Expert Panel. Some phase 1 and 2 DDPs set up the Expert Panel 
... to make sure that all the work that was carried out was moderated and verified by group experts in the field.

(Interviewee from phase 2 DDP)

Retail Business DDP set up a sub-group of their Employer Advisory Group to discuss customer services within their Diploma line. Hair and Beauty DDP set up six Focus Groups, relevant to their six parent industries. These were, for example, Hair Focus Group, Nail Focus Group and Spa Focus Group.

Regular commitment though desirable, was not always achievable. There is evidence that some employers were able to attend meetings of the particular working group on a regular basis whereas others were replaced by colleagues as needed or there was no employer representation during the meeting. Although many DDPs experienced considerable flux in the quality and quantity of employer engagement, overall they were satisfied with the level of employer input. There is interview and observation evidence that the participating employers were enthusiastic about the opportunity to engage in such an innovative educational reform initiative and were committed to support the DDP's work.

DDPs were faced with some difficulties because of employers' lack of previous experience with qualification development. Whereas the development of the initial document (Line of Learning Statement) comprising the content of the particular Diploma line was considered as an innovative and enjoyable activity, when this document was developed in to the Criteria (the second stage document within the qualification development) much of the content was considered to be lost by employers. The Criteria is a more technical document, on the basis of which the Awarding Bodies develop the qualification. Nevertheless this development was unexpected for many of the employers.

We certainly had our [content] specified to a level of detail which was greater than the final form ... standard format content. So we effectively had to take stuff out, and that was a point at which we had some severe misgivings, because it was felt that losing some of what we were saying risked the possibility that the qualifications to be developed from the shorter specification would not meet our entire objectives. (Phase I Interviewee) 
... learning from what's happened in the past, that some of the Line of Learning Statements, some of the richness

... the potential richness, seems to me to have been possibly lost, because we've been so concerned in the later stages of the production of the Statement to think about how good they would be for ... as a basis for the Criteria. ... in some cases, they're a bit ... they may have ended up being a little bit too criteria-like. There's some sort of fudging between the two types of documents, which has happened because of this drive to make sure that mistakes from previous phases are not repeated. (Phase III Interviewee)

In addition to employers directly impacting on the development of the qualification for the particular Diploma line through the DDPs, DDPs made considerable efforts to consult with a wider range of employers from their sector. Consultation was often done through the employers' network of the Sector Skills Councils (SSC). It was often tailor made to the sector and to the type of employers of which that particular sector consisted. Interviewees mentioned on-line consultation with follow-up telephone interviews, paper questionnaires, in-depth interviews with smaller numbers of employers, regional events and conferences. Some DDPs were seeking up-to-date information on skills' demands on the labour market, others asked employers for feedback on materials produced by the DDP and on certain sections of the content, i.e. Line of Learning Statement. Through regional events DDPs were hoping to attract feedback from local businesses, and they often ran smaller scale evening or breakfast time events for small and medium size enterprises (SME).

According to the interview data, SMEs were hard to reach by many DDPs. The incorporation of SMEs' needs and views is particularly important as in 2007, SMEs accounted for more than half of the employment and turnover in the UK (Department for Business Enterprise and Regulatory Reform, 2008). However, interview data confirms that they often lack time and resources as one interviewee noted:

The communication routes to [the SMEs] are extremely difficult. When you get to them , they have very few specialist [Human Resource] or training people, and one of the key routes to them is through representative associations, rather than directly to the employers themselves. (Phase 1 interviewee) 
However, in Diploma lines such as Hair and Beauty and Sport and Active Leisure where SMEs dominate the sector, consultations with SMEs were reportedly positive.

In summary, DDPs made considerable effort and spent time, energy and sometimes financial resources to develop effective consultation strategies. While the events reached out to many employers, the participating employers cannot be considered as fully representative samples for their cohort. However, many of the interviewees felt satisfied with the range and outcomes of the consultation.

Following the outline of employer engagement in Diploma development in the pre-delivery stage, the next section will concentrate on two small scale, in-depth consultation approaches with employers as specific examples from the overall consultation process with employers. Focusing closely on two specific tasks, it will reiterate some of the ideas of employer engagement described previously and will further detail others, such as gaining access to employers and describing company-specific preferences for the Diploma in Languages and International Communications.

\section{Phase 4 Diplomas: consultation with employers}

Phase 4 Diplomas (Humanities, Languages and Science) represent different types of Diplomas from the initial 14. Whereas the original 14 lines are sector related, the three new Diplomas have cross-sectoral relevance. Therefore, the target employer cohort is vast, and employers from any industry area can offer relevant and useful input into any of the three Diploma lines.

For all three lines of learning a range of approaches have been implemented to encourage employer engagement. These include the establishment of an Employer Advisory Group within the DDP, consultation events, market view research including face-to-face interviews, focus group discussion and questionnaires. Overall the consultation focused on what employers need, what they want, what they think of the proposed content and processes, and the extent to which the new Diploma meets their needs now and in the future. 


\section{Diploma in Languages and International Communication}

There have been two approaches in gathering information from employers concerning the Diploma in Languages and International Communication in November 2008 (Laczik, 2009), which formed part of the DDP's wider consultation strategy. Employers were approached with a questionnaire, 7 employers attended a focus group discussion and further 6 employers were interviewed in-depth in order to develop a better understanding of the extent to which employers value language skills and intercultural understanding in the workplace. Because of the small number of employers who responded to this part of the consultation and the self-selected nature of sampling the findings are indicative and exploratory rather than conclusive. It is not only interesting what employers have said, but also what have been the obstacles to prevent them to respond to the DDP's request. These pieces of work represent, however, only a fraction of what the DDP's consultation and research strategy entailed to support the qualification development of the Diploma in Languages and International Communication.

\section{Gaining access to employers - Sampling}

A small group of employers was approached with the consultation questionnaire in November 2008. These individuals had signalled that they would be happy to get involved in the consultation process concerning the new Diploma in Languages. Some of them were selected on the basis of having a track record of sending their employees to language and/or intercultural understanding courses.

Considerable time and effort was put into identifying and interviewing employers. Even though the consultation used convenience sampling, effort was made to cover a range of industries and businesses. Although only six employers were interviewed in depth, they represented a variety of backgrounds: public and private sector, large and SMEs, and a self-employed individual. Similarly, they represented a variety of industry areas and professions, such as financial institutions, public services, graphic design, travel and tourism and hospitality and catering. Consultation participants represented areas of employment likely to benefit from language and intercultural skills. 
Employers were fundamentally supportive and willing to be interviewed. Nevertheless, negotiating a 2030 minutes gap in their busy work schedule was not always an easy task. One employer was managing a small hotel, managing staff and was responsible for the day-to-day running of the place. Some were working in managerial posts and had to attend meetings regularly. All these added difficulties when negotiating possible times for the interview. The interviews were conducted in early 2009 , and there was one employer who stepped back from being interviewed because of heavy job losses at his company.

In summary these interviewed employers demonstrate a broad range of challenges encountered by the researcher, and offer real examples of employer engagement. Some of these difficulties are due to individual circumstances, whereas others to the current economic climate. Despite employers' best intentions to contribute to education, their foremost aim is to keep their company alive, and to generate income.

\section{Content of consultation - semi-structured interviews}

The aim of the employers' consultation was manifold. Some of the objectives were to identify and explore:

- current provision in languages and their value to employers;

- employers' views on using languages in the work place;

- employers' views on the importance of language skills and intercultural understanding in the workplace;

- Personal Learning and Thinking Skills

- some of the opportunities and barriers to work experience: this will be an integral part of the Diploma in Languages qualification;

- some possible alternative titles for the Diploma in Languages.

Employers were approached who were likely to employ people with language skills because of the nature of their business, such as travel and tourism, interpretation and translation and businesses which were 
dealing with customers internationally. Therefore, they were more likely to have a view on supply and demand in the labour market for employees with language and intercultural skills.

Given the cross-sectoral character of the Diploma in Languages and International Communication, the issues for the researcher are: a) to what extent can the consultation cover the richness of employers' views, and b) to what extent can these be included in the content of the qualification?

The very different views employers expressed during the interview will be exemplified and discussed below. Examples will point to difficulties in negotiating and reconciling differences in views and opinions, and in incorporating those into the content of the Diploma. All questions were posed asking interviewees about their personal experience within their company. The responses to two interview questions will be briefly outlined and discussed next.

What types of languages are most useful for your organisation?

Evidence shows that employers use a large number of well-known or lesser-used languages, depending on their business interest. One interviewee reported the use of over 25 different European languages by his company, including Czech, Finish and Norwegian. Another interviewee pointed to Arabic, stressing the huge market, where 'having a language like [Arabic] could be an advantage'. The importance of community languages was stressed only by one employer, who concentrated on serving the local community. Other interviewees found community languages useful only in the international setting. Specifically, if they had business activities in the country of origin, i.e. in India or Pakistan. Similarly, a wide range of lesser used languages were mentioned by employers, when they had business interests in the region. These included for example Mandarin, Hebrew, Kurdish, and Japanese. However, French clearly was considered as one of the most important and most used languages by employers having international interests. 
Another common response by the interviewees was the use of English as one of the main international business languages. International business partners who speak English reduce the necessity for employees who speak another language. At the same time it is acknowledged that there are nationals, who, in general, are less fluent in English. As one interviewee from the hospitality and catering sector noted:

We need Italian. As it happens most Italians do not speak English. They are the least proficient in English, unlike German or French. ... Russian clients do speak English but they are not as proficient in English.

Clearly, employers point to languages that they need for their business and/or when their business partners or clients are less proficient in English. Data also highlight the vast number of different languages employers would be able to make use of. Nevertheless, each employer considers a different language important according to their particular business needs. The following section discusses the level of proficiency employees need to demonstrate in their job.

To what extent is proficiency in language skills (i.e. other than English) useful/important to your organisation?

The importance of proficiency in language skills varies according to the company's needs to fulfil specific activities. It can differ within the company from one role to another, from one department to another. In addition to language skills, many employers distinguish between language skills and cultural awareness:

For some roles it is absolutely essential and high level of fluency is required, and other roles there are no language requirements but clearly cultural awareness is very favourable. (Interviewee from the Public Sector)

There are clearly times and tasks when most interviewees needed the highest level of proficiency in a language to maintain quality and to achieve the goal.

For certain tasks to achieve precision and maintain sensitivity native speakers are preferred. The usefulness of having multilingual employees is clear from the data. They contribute positively to formal and informal settings within the business. Proficiency in the language is often important especially when 
using technical terms. As one employer points to the very core of the issue, a native speaker can solve the problem in one person, otherwise communication may become an issue:

We had a French programmer here. When he was working for us the communication channels between us and the client were incredibly strong - never any problem. When he left, communication and programming became a bit difficult because it's so technical. If you are not proficient in the language you always have to go through the marketing people to get to the IT people. Perhaps the IT people do not speak so good English.

Another group of employees where a high level proficiency is essential is in interpretation. The employer clearly pointed out:

We prefer the native speakers but there are cases where people speak more than one language. Someone from Iraq: first language is Kurdish but they also often speak Arabic as well. Initially we go for the native language, but later they may add a second language. (Public Services)

In the hotel industry, for example, employees who deal with guests, receptionists, waitresses, managers ideally have an intermediate level of two languages. If employees have three languages at basic level, that may be considered sufficient. As a representative of the sector said: 'The more languages the better.' In addition it is reassuring for guests 'they know if they are ever in trouble or need help they can communicate with us in their own language'.

Again, another employer pointed out that communicating in another language just makes that difference between having or not having, the business partner:

Not everybody works in our industry speaks good English. It is ok at the top level, you have no problem, but it is at the lower level where you have a stumbling block. The lower level (regional offices) have problems dealing with you, then they do not want to deal with you. If this gets back to the national office, then the question is asked, 'Is this the right organisation to deal with? Maybe we should look at another organisation.' (Interviewee from a Graphic Design and IT company) 
Many interviewees noted that it is an advantage to engage in direct communication with new and existing business partners in their mother tongue, and not in English. Business partners and clients appreciate the gesture, especially if they are not proficient in English.

Employers offered frank opinions on the language proficiency level they required to keep their customers and business partners happy. At the same time, the scale of language skills stretches from basic to native language speaker, and from speaking one language at a native level to speaking many languages at a basic level.

The task to consolidate the consultation data and build it into the Diploma for Languages and International Communication stays with the DDP. It was demonstrated that the need for languages are very individualistic and reflects the nature of the business. Next, an example of employer consultation in Humanities and Social Sciences will be discussed.

\section{Diploma in Humanities and Social Sciences}

The ‘Additional Employer Research' study for the Diploma in HSS (Stanley, 2009) formed part of a broader range of consultation activity which included on-line and event consultations involving a variety of employers (Creative and Cultural Skills, 2009). The study explored what employers would like included in the HSS Diploma in terms of subject knowledge, generic skills and transferable skills.

Organisations were contacted which offered a potential career route for young people from a Humanities and Social Sciences background. Participants included representatives from a Civil Service department, a professional body for legal executive training, an apprenticeship scheme for a local authority, a large law firm, the army careers service for officer training, a professional body for HR managers, a television company, an SME organisation, professional teaching organisation, a specialist recruitment agency and a commercial property management company. As learners with a Humanities and Social Sciences background traditionally enter careers related to these disciplines at graduate or postgraduate level, it proved a challenge to identify potential HSS Diploma career destinations that offered entry at both Level 3 16 
and graduate level which would enable participants to comment on employer needs within a Level 2 or 3 Diploma. Nevertheless, most organisations represented in the study offered entry at both Level 3 and graduate level and three offered entry at Level 2. Each of the 11 participants was separately interviewed by telephone using a common schedule.

\section{Employer skills needs in Humanities and Social Sciences}

During the interviews, employers were presented with a generic Personal Learning and Thinking Skills (PLTS) list (see Figure 1 below), and a list of transferable skills or processes specific to Humanities and Social Sciences (see Figure 2 below) which had been identified during the development process for the Diploma in HSS. Participants were asked to comment on the relevance of these lists to their sectors, and whether they perceived any skills to be missing from the lists. Their responses throw light on the potential challenges of formulating qualification outcomes that relate to most employers.

Figure 1. HSS Diploma Generic Skills (PLTS)

\begin{tabular}{|l|l|}
\hline Skills & Examples \\
\hline Working with others & $\begin{array}{l}\text { Reaching agreement, adapting behaviour to suit role, } \\
\text { leadership }\end{array}$ \\
\hline Independent enquiry & Investigate problems or events \\
\hline Effective participants & Find and advocate practical solutions to problems \\
\hline Creative thinking & Generate ideas, explore possibilities \\
\hline Reflective thinking & Review experiences, invite feedback \\
\hline $\begin{array}{l}\text { Initiative and self- } \\
\text { management }\end{array}$ & Organise time, work towards goals \\
\hline
\end{tabular}


Participants responded favourably to the generic PLTS skills list (Figure 1 above). Eight of the eleven participants agreed that all of the generic skills listed were critical to their sector. However, most participants suggested additions to the list. Furthermore, while suggesting additions, five of the eleven participants reframed or re-emphasised skills that were already on the list. Interestingly, some of these participants appeared not to relate to the description of a skill on the list as they suggested the same skill but expressed it in a different way. For example, one participant added 'identifying and communicating solutions' which is very similar to the 'find and advocate practical solutions to problems' given in the list. Another added 'team leadership' which was already incorporated within 'working with others' 'leadership'. Others added suggestions which would be encompassed by one of the six generic skills, for example 'meeting deadlines' which would be covered by 'initiative and self-management' - 'organise time, work towards goals'. These re-framings, along with other varied additions to the skills list, indicate the potential challenges involved in framing generic skills to which most employers can easily relate. However, the exercise was a useful opportunity to gather views on how the generic skills list could be developed and refined to suit employers generally.

Figure 2. Humanities and Social Sciences Transferable Skills or Processes

\begin{tabular}{|l|l|}
\hline Skills & Examples \\
\hline Enquiry and Research & Research design, framing questions \\
\hline Self-understanding & $\begin{array}{l}\text { Knowing your own strengths and } \\
\text { weaknesses }\end{array}$ \\
\hline Using Evidence & $\begin{array}{l}\text { Analysis, presentation } \\
\text { Contd.../ }\end{array}$ \\
\hline
\end{tabular}




\begin{tabular}{|l|l|}
\hline Explanation and knowledge building & $\begin{array}{l}\text { Finding causes, recognising patterns or } \\
\text { similarities between situations }\end{array}$ \\
\hline Interpretation & Of documents, rules \\
\hline Understanding of others & $\begin{array}{l}\text { Understanding different perspectives and } \\
\text { motivations }\end{array}$ \\
\hline Reasoning and criticism & Developing and evaluating arguments \\
\hline $\begin{array}{l}\text { Decision making and intelligent } \\
\text { action }\end{array}$ & $\begin{array}{l}\text { Advocacy, leadership, evidence based } \\
\text { action, managing change }\end{array}$ \\
\hline
\end{tabular}

Most participants responded readily to the HSS transferable skills list (Figure 2 above). Eight of the eleven participants perceived that these transferable skills were generally relevant to their sector.

However, participants reported varying patterns and levels of application of all of these skills across the sectors represented. For example, five participants specified 'Self-understanding', 'understanding of others', 'enquiry and research', and 'using evidence' as critical to their sector. Another three participants specified two different skills - 'decision-making and intelligent action' and 'explanation and knowledge building' - as critical for their sector. Finally, two participants cited 'interpretation' as being critical, and 'reasoning and criticism' is cited by one participant as critical. Levels of criticality depended on the nature of the sector or the level of the job. For example, some skills were more relevant for lawyers, some for policy-making departments and some for property development companies. Furthermore, two participants reported a limited need for these skills from new entrants in their organisation due to the level of the jobs involved. These findings highlight the potential challenges involved in creating transferable skills lists that would appeal across different sectors and different levels of job. The findings also point to the challenges of attempting to relate an academic qualification to employer needs when its subject areas are not related to any particular sector. 
Responses to the HSS subjects list, the 16 subjects

The study also explored what employers would like included in the HSS Diploma in terms of subject knowledge. Participants were asked which of the HSS Diploma's potential subjects would be useful to employees in their organisations or sectors. At the time of the research there were 16 potential subjects to be included in the Diploma in HSS, namely Archaeology, Citizenship, Classical Civilisation, Classics, Economics, English Language, English Literature, Geography, History, Law, Philosophy, Politics and Government, Psychology, Religious Education, Sociology, and World Development

Over half of the participants judged Citizenship, Economics, English Language, English Literature,

Politics, Psychology, Sociology and World Development to be useful to their employees. Law was judged as useful by half of the participants. Geography was chosen by four participants, Religious Education and History were chosen by three participants, and Archaeology, Classical Civilisation and Philosophy were each chosen by two participants. Most participants valued the transferable skills generally associated with the Humanities and Social Sciences subjects.

Responses suggest that when participants were presented with the range of HSS subjects they identified with those which seemed more relevant and useful but their responses were influenced by their particular subject background. This is evident in the case of less frequently chosen subjects such as Archaeology and History. For example, three participants from a Humanities background singled out History as developing valuable transferable skills such as research and analytical skills and the ability to formulate and present a case whereas most participants judged History to be irrelevant to their sector. Similarly, most participants judged Archaeology to be irrelevant whereas two participants selected Archaeology as relevant as they were aware of what the study of Archaeology entails, namely its statistical and mathematical applications. These findings highlight the difficulties of 'selling' qualifications to employers in terms of subjects and again point to challenges involved in creating academic qualifications which would appeal to employers. 
At this point it should be emphasised that despite the study's heterogeneous findings, all participants indicated that they generally valued the learning outcomes promised by the HSS Diploma. Most participants responded readily to the different outcomes that were offered, which suggests that these outcomes are likely to be generally understood by employers. The study also provided insights into employer perceptions of skills shortages among recent recruits together with perceptions of how current qualifications develop skills. However, these areas will not be discussed within the scope of this article. In summary, the HSS additional research with employers provided an insight into the way that employers perceive the learning outcomes of the HSS Diploma. However, participant responses to the outcomes lists highlight that meeting the varied needs of employers in qualification design is problematic as employers are not a homogenous group - they represent different sectors of industry - high skill and low skill, different sizes of company, variations across different sectors, and variations within the same sector. Additionally, the study draws attention to the challenges involved in creating an academic qualification which would appeal to employers from different sectors. Furthermore, four of the participants were representing professional organisations. While these participants offered an efficient opportunity to capture feedback from their sectors, the extent to which proxies from professional organisations can represent the heterogeneity of their own sector is questionable. Finally, it needs to be noted that many respondents agreed to participate because they were interested in the concept of the Humanities and Social Sciences Diploma and wanted to contribute - some were from a Humanities and Social Sciences background and others expressed an interest in the qualification. Because of the self-selecting nature of the sample of respondents, their views are not necessarily representative of employers.

On the other hand, it should be highlighted that the research provided a useful opportunity for employers to communicate what they valued and did not value about the proposed HSS Diploma and enabled a better understanding of employer perspectives. It should also be noted that its findings relate to a small survey 
and do not represent an evaluation of the wider contribution of employers to the design of this qualification.

\section{Conclusion}

Employer engagement has possibly reached its height by attempting to involve them in qualification development. In this article we have argued that employer engagement is not a new phenomenon. What is new is the level at which employers are expected to engage. We have exemplified and discussed employers' contributions in the context of the new Diplomas, a number of which are still being developed and are expected to be in schools only by 2011 . Overall Diploma development is particularly interesting as these new qualifications were meant to be employer-led clearly pointing to policy makers' high expectations from employers.

Involving employers in the qualification development could be seen as a positive aspect, bearing in mind the government's agenda for recognising skills. Employers are a heterogeneous group bringing a range of different views, ideas and contributions to the process of qualification development often quite sector specific. It has been argued that many employers were committed to make their input even though only few had experience of, or understood, qualification development. In the context of the Diplomas, while the first 14 Lines of Learning are sector specific, the Phase 4 Lines are not. Humanities, Languages and Science Diplomas are cross-sectoral, hence the identification of employers, and the reconciliation of employers' views and opinions within the qualification proved to be more challenging. Nevertheless, young people with qualifications into which employers have had such detailed and in-depth input should be attractive within the labour market. This however, can only be judged once young people are out in the market place with Diploma qualifications in their hands. 
All three examples referred to in this article similarly highlight that engaging employers at this high level assumes that employers have the capacity, inclination, willingness to learn and negotiate with educationists and so on, and are able independently to sustain their contribution. Simultaneously, there was the opportunity for injections of employer input for smaller very specific tasks. Nevertheless, regular and sustainable employer engagement is preferred. The article highlights that each of the Diploma Development Partnerships have developed comprehensive line-specific consultation strategies with employers, and they have experienced varied responses. Only few employers can commit to regular engagement but many saw this as an opportunity to impact on education. Within the Diploma development SMEs have received special attention because of their importance and contribution to the UK economy. It was argued that SMEs have different possibilities from large businesses when it comes to engaging with education. Nonetheless their contribution at local level is widely recognised.

Employers were invited to contribute to qualification development. Even though they had good intentions and an overwhelmingly positive attitude, because of personal and economic circumstances their engagement can be patchy and changes according to companies' demands and the economic climate. This is often unintentional, and can be attributed not only to individuals but to the changing environment within and outside their company.

In summary, the article points to a possible mismatch between policy makers' expectations from employers at macro level, and what in fact happens at local, micro level. Given the current economic climate, the question is raised whether a saturation point has now been reached by the constant demand on employers. Bearing in mind that employers' engagement and contribution in the Diplomas is voluntary, and they may have exhausted their possibilities. The introduction of incentives, such as offering them a tax break as a return, could secure their continuous engagement that is highly valued at macro and micro level. In other words, incentives might help to convince employers that partnerships between employers and education are 'a two-way street' (DCSF, 2008a). 


\section{Bibliography}

Creative and Cultural Skills (2009) Diploma in Humanities and Social Sciences Line of Learning Consultation Report web page. Available online at:

www.humanitiesdiploma.co.uk/line-learning-statement-consultation-report. (accessed 18th August 2009).

Department for Business Enterprise and Regulatory Reform, (30 July 2008); Statistical Press Release.

Department for Children, Schools and Families (DCSF (2008a) Building Stronger Partnerships.

Employers: How You Can Support Schools, Colleges, Children and Families (London, DCSF).

Department for Children, Schools and Families (DCSF) (2008b) Employer Engagement: A Guide for Diploma Consortia (London, DCSF).

Department for Education and Skills (DfES) (2003a) Developing a national skills strategy and delivery plan: progress report (London, DfES).

Department for Education and Skills (DfES) (2003b) 14-19: opportunity and excellence (London, DfES).

Department for Education and Skills (DfES) (2005). 14-19 Education and Skills. (London: Stationery Office).

direct,gov.uk (2009). Diploma website. Available online at: 
http://yp.direct.gov.uk/diplomas/other_audiences/employers/ (accessed $4^{\text {th }}$ August 2009).

Ertl, H., Stanley, J., Huddleston, P., Stasz, C., Laczik, A., Hayward,

G. ( (2009) Reviewing Diploma Development. Evaluation of the Design of the Diploma Qualifications (London,DCSF).

Her Majesty's.Treasury (2004) Supporting Young People to Achieve: Towards a New Deal for Skills (HMSO: London).

Hodgson, A. \& Spours, K. (2007) Specialised diplomas: transforming the 14-19 landscape in England? Journal of Education Policy, 22:6, 657-673.

House of Commons Education and Skills Committee (2007) 14-19 Diplomas, Fifth Report of Session 2006-07, (London: The Stationary Office).

Keep, E. (2005) Reflections on the curious absence of employers, labour market incentives and labour market regulation in English 14-19 policy: first signs of a change in direction? Journal of Education Policy, 20:5, 533-553.

Laczik, A. (2009). Diploma in Languages: Employer consultation. (Internal Report), Centre for Education and Industry, Warwick University

Lloyd, C, (2008) Recruiting for fitness: qualifications and the challenges of an employer-led system, Journal of Education and Work, 21:3, 175-195. 
Muir, F. (2009a) Market View for the Diploma in Languages, Centre for Education and Industry, University of Warwick.

Muir, F. (2009b) Secondary research to establish content for the Diploma in Languages. Centre for Education and Industry, University of Warwick.

Nuffield 14-19 Review (2007) Nuffield Review of 14-19 Education and Training, England and Wales: Issues Paper 1: The New 14-19 Diplomas. Available online at: http://www.nuffield14-19review.org.uk/files/documents168-1.pdf (accessed $19^{\text {th }}$ August 2009).

Payne, J. (2008) Sector skills councils and employer engagement - delivering the 'employer-led' skills agenda in England, Journal of Education and Work, 21:2, 93-113.

QCA, DfES, and Skills for Business. 2005. 14-19 Specialised Diplomas. Guidance for Diploma Development Partnerships, $2^{\text {nd }}$ edition. London: QCA

QCA, DfES, and Skills for Business. 2006. 14-19 Specialised Diplomas. Guidance for Diploma Development Partnerships, Phase 2. Issue 1. London: QCA

QCA, DfES, and Skills for Business. 2007. 14-19 Specialised Diplomas. Guidance for Diploma Development Partnerships, Phase 3, Issue 1. London: QCA

Scesa, A.\& Williams, R. (2008) Engagement in course development by employers not traditionally involved in higher education: student and employer perceptions of its impact (London: EPPI-Centre, Social Science Research Unit, Institute of Education, University of London). 
Stanley, J. (2009) Market Research Appendix F: Additional Research with Employers. Available online at: http://www.humanitiesdiploma.co.uk/files/Market\%20Research\%20Appendix\%20F.doc_0.pdf (accessed 18th August 2009). 